\title{
A Recent Advance in Image-Guided Locoregional Therapy for Hepatocellular Carcinoma
}

\author{
Yaoping Shi Bo Zhai \\ Department of Interventional Oncology, Renji Hospital, Shanghai Jiaotong University \\ School of Medicine, Shanghai, China
}

\author{
Key Words \\ 125I seed · Ablation · Hepatocellular carcinoma - Image-guided locoregional therapy · \\ Local ablative therapy · Radiofrequency ablation - Transarterial therapy
}

\begin{abstract}
Background: Hepatocellular carcinoma (HCC) is the fifth most common cancer worldwide and the third most common cause of cancer-related deaths. Hepatic resection and liver transplantation are considered to be the preferred treatment for HCC. However, as novel therapeutic options such as image-guided locoregional therapies have emerged and been refined, the manner in which HCC is treated has changed dramatically compared with what it was considered just 2 decades earlier. Summary: This study reviews the current results of various imageguided locoregional therapies for treating HCC, especially focusing on thermal ablative and transarterial techniques. Key Message: Advances in image-guided locoregional therapies, including local ablative therapy and transarterial therapy, have led to a major breakthrough in the management of HCC. Both survival rates and cure rates of patients with HCC have improved markedly since the introduction of these techniques. Practical Implications: Radiofrequency ablation is currently considered as an alternative to surgical resection for patients with early-stage HCC. A newer technique of ablation such as microwave ablation is increasingly being used, especially for large HCC. Transarterial chemoembolization has become a standard care for asymptomatic patients with multinodular tumors in intermediate-stage disease, and transarterial radioembolization has become the method of choice in HCC cases with portal vein thrombosis. Moreover, combination treatment modalities, such as thermal-based ablation combined with transarterial chemoembolization or ${ }^{125}$ I seed implant brachytherapy, may further broaden their clinical indications for HCC. Moreover, use of localized radiation in combination with thermal ablation has been reported to improve tumor control and longterm survival.




\section{Introduction}

Major improvements have been made in the management of hepatocellular carcinoma (HCC) during the last several decades. Advances in early detection, imaging techniques, and novel therapies have improved patient selection and enabled evidence-based treatment approaches [1]. Five interventions reach the highest level of evidence, being worldwide accepted recommendations for treating HCC [2]: resection, liver transplantation, percutaneous ablation with radiofrequency, transarterial chemoembolization (TACE), and systematic therapy with sorafenib. Hepatic resection still remains the first-line option for patients with early-stage HCC as defined by the Barcelona Clinic Liver Cancer staging system [3]. However, such surgery requires wide resection margins, and underlying cirrhosis limits the volume of liver that can be resected without causing liver failure [4,5]. Liver transplantation has been established as an alternative curative treatment for small HCC associated with cirrhosis, offering excellent survival results in patients who met the Milan criteria [6]. Nevertheless, its use has been restricted by the severe shortage of organ donors, which causes longer waiting times and increases dropout rates as a result of tumor progression while waiting for a graft. Conventional chemotherapy was proven ineffective for this malignancy [7] due to the coexistence of liver cirrhosis in most patients, which makes them more susceptible to toxicities associated with drugs, even at early stages of liver failure. The use of image-guided locoregional therapies has developed primarily due to the limited applicability of surgical treatment for HCC. When surgery is precluded, image-guided locoregional therapies, which can be broadly categorized into local ablative therapies and transarterial therapies, are recommended as the most appropriate therapeutic choice to improve the prognosis of patients.

\section{Local Ablative Therapy}

\section{Radiofrequency Ablation}

Radiofrequency ablation (RFA) is the most common thermal ablation modality worldwide and is currently considered the best therapeutic modality for patients with early-stage HCC who are not candidates for surgical intervention [8,9]. RFA relies on thermal heat created by an electrical current passing through the electrode embedded in the tumor. Temperatures between 60 and $100^{\circ} \mathrm{C}$ are generated by the high-frequency alternating current, which induces frictional heating when the ions in the tissue attempt to follow the changing directions of the alternating current [10]. Five randomized controlled trials (RCTs) compared RFA and percutaneous ethanol injection (PEI) for treating early-stage HCC. The results of these investigations consistently showed that RFA is more effective than PEI, leading to better local control of the disease [11-15]. In addition, four independent meta-analyses [16-19] that included all RCTs confirmed that RFA offers a better local control and survival benefit for early-stage HCC in comparison with PEI, thus establishing RFA as the standard percutaneous technique in these patients. An open question is whether RFA can compete with surgical resection as first-line treatment. Head-to-head comparisons between RFA and resection have been conflicting, with one randomized trial [20] demonstrating essentially no difference in overall survival (OS), and the other [9] indicating improved results for surgery over RFA. Similar conflicts are found in two meta-analyses, with one [21] showing equivalent survival rates despite higher rates of local recurrence with RFA, and the other [22] demonstrating better survival rates in surgical patients with tumor sizes $\geq 3 \mathrm{~cm}$ in diameter and equivalent rates in smaller tumors.

It has been reported that lesions $>3 \mathrm{~cm}$ were not as effectively treated at the margins by RFA [23]. The incomplete ablation is largely attributed to the 'heat sink' effect, a reduction in 
Shi and Zhai: A Recent Advance in Image-Guided Locoregional Therapy for Hepatocellular Carcinoma

tissue temperature due to the conductive effects of adjacent vessels, typically described as $\geq 3$ $\mathrm{mm}$ in diameter [24]. Histologic studies performed with liver specimens from patients who underwent RFA as bridge treatment before transplantation showed that the presence of large ( $\geq 3 \mathrm{~mm}$ ) abutting vessels results in a decrease of about $50 \%$ in the rate of complete tumor necrosis because of the heat loss due to perfusion-mediated tissue cooling in the area to be ablated [25]. The methods to overcome the heat sink effect include pharmacologically decreasing blood flow [26-29], temporary vascular balloon occlusion [30, 31], and intraarterial embolization [32, 33]. A combination of TACE followed by RFA is the most widely used technique aiming to minimize heat loss due to the heat sink effect, and the effectiveness of this combination treatment has been confirmed by several investigators [34-39]. In theory, the decreased blood flow induced by transarterial embolization reduces heat loss, increasing the ablation volume of the tumor, while the addition of TACE enhances the nearby control of satellite lesions [37, 40]. An RCT [41] compared RFA combined with TACE and RFA alone for treating intermediate-sized $(3.1-5.0 \mathrm{~cm}) \mathrm{HCC}$. The results of this investigation showed that RFA combined with TACE is more effective than RFA alone for extending the ablated area in fewer treatment sessions and decreasing the local tumor progression rate. Another very recent RCT [42] showed that TACE-RFA was superior to RFA alone in improving survival for patients with $\mathrm{HCC}<7 \mathrm{~cm}$. Moreover, several independent meta-analyses [43-46], including the RCTs available for RFA plus TACE compared with RFA alone, confirmed high-quality evidence suggesting that TACE in combination with RFA improved survival outcomes compared with RFA alone for patients with HCC, particularly for tumors $>3 \mathrm{~cm}$ in size. An alternative strategy using localized radiation in combination with RFA has also been studied [47]. Results from a recent RCT [48] demonstrated better local and intrahepatic tumor control and long-term survival in combination therapy $\left({ }^{125}\right.$ I seed implantation and RFA) compared with RFA alone.

RFA is a safe procedure with a very low death rate of $0.2 \%$ and a major complication rate of $2.2 \%$, as reported in a large multicenter study [49]. Clinical experience suggests that RFA of HCC tumors in a subcapsular location or adjacent to extrahepatic organs such as the gastrointestinal wall and gallbladder is associated with an increased risk of major complications due to heat injury [49-51]. The limitations of RFA for such high-risk HCC can be addressed by performing surgically assisted RFA using a laparoscopic approach [52, 53]. The ability to manipulate the perihepatic environment can protect structures such as the colon, stomach, small bowel, and diaphragm from transmitted heat. It also allows for potential removal of the gallbladder prior to RFA, preventing injury and heat sink. Thus, laparoscopic RFA should be recommended for patients with high-risk HCC.

\section{Microwave Ablation}

Microwave ablation (MWA) is emerging as a valuable alternative to RFA for the thermal destruction of HCC; it employs electromagnetic wavelengths in the frequency range of 900-2,450 MHz. Rapid directional current changes in the microwave electrode cause surrounding water dipoles to oscillate, resulting in heat generation leading to cellular coagulative necrosis [54]. Unlike RFA, MWA is not limited by the conductive property of tissues, and, therefore, a high tissue temperature can be more easily achieved [55], theoretically allowing for an increased efficacy of ablation in comparison to RFA. In addition, MWA is not as influenced by heat sink effects as RFA is [56], and is capable of creating a larger ablation zone [57]. Moreover, because MWA does not depend on the passage of electricity through tissues as RFA does, multiple applicators can be used simultaneously to create larger ablation zones and shorten the procedural time. Faster ablation times, larger ablation zones, and higher intratumoral temperatures have been observed with MWA in ex vivo bovine $[58,59]$ and in vivo porcine [60] animal models. Given its increased efficacy in ablation and shorter 
time to achieve ablations, MWA has increasingly been used in treating HCC [61-67]. Liang et al. [62] evaluated a series of 288 patients with HCC who underwent percutaneous MWA and demonstrated 1-, 2-, 3-, 4-, and 5-year cumulative survival rates of 93, 82, 72, 63, and 51\%, respectively. The authors considered a high probability of long-term survival of patients with a single lesion $\leq 4.0 \mathrm{~cm}$ in maximum diameter and Child-Pugh class A cirrhosis. Numerous studies have compared MWA with RFA for treating HCC and found similar disease-free survival, cumulative survival, and complication rates in the two groups [68-74]. However, so far, only one RCT [68] has compared the efficacy of MWA with that of RFA, in a series of 72 patients (36 RFA/36 MWA) with equivalent background demographics and mean tumor sizes. Although no statistically significant differences were observed with respect to therapeutic effects, complication rates, and rates of residual untreated disease between the two procedures, a trend favoring RFA was recognized in that study regarding local recurrence and complication rates. It has to be pointed out that the MW technology has improved markedly since this trial [75], and two prospective RCTs (NCT02539212 and NCT01340105) comparing the two techniques (RFA vs. MWA) for HCC are underway, which may obsolete the aforementioned results.

Given that MWA can create a larger ablation zone, MWA alone or combined with TACE has increasingly been used in treating large HCC [76-78]. Abdelaziz et al. [78] recently performed a study to compare the efficacy and safety of percutaneous MWA with TACE for large tumors $(5-7 \mathrm{~cm})$ and demonstrated better results for MWA than TACE in managing large HCC lesions. Another retrospective study [77] compared the outcomes of TACE combined with MWA (TACE-MWA) with TACE for treating unresectable large HCC ( $\geq 5.0 \mathrm{~cm}$ in diameter). The results showed that TACE-MWA had advantages in prolonging OS, with satisfying times to progression and improving liver function. However, further prospective studies are required to confirm the findings of these studies. A large multicenter RCT (NCT02630108) is ongoing to compare the efficacy and safety of TACE alone and TACE combined with synchronous multipoint MWA/RFA for large liver tumors.

\section{Cryoablation}

Cryoablation, which relies on freezing temperatures to induce tumor cell death, is the oldest local ablative technique for benign or malignant tumors [79]. Percutaneous cryoablation is believed to ablate cancer cells by several mechanisms including direct cell injury, vascular injury and ischemia, apoptosis, and immunomodulation [80, 81]. The advantages of cryoablation, compared with other ablative techniques, are as follows: (1) it allows for visualization of the 'ice ball' using noncontrast computed tomography [82], ultrasound [83], or magnetic resonance imaging [84] monitoring, which permits more precise evaluation of the ablated zone in real time; (2) it causes less pain and can be performed under moderate sedation, making it feasible for patients who are poor candidates for anesthesia [85], and (3) it maintains cellular integrity of connective tissue in the vessel walls, or adjacent visceral linings, such as the gallbladder, bowel, and kidney [86]. Despite the technical advantages, cryoablation has a potentially life-threatening complication, cryoshock syndrome, which is characterized by thrombocytopenia, multiorgan failure, and disseminated intravascular coagulopathy, specific for cryotherapy in large HCC [87, 88]. In addition, since cryoablation probes are needle shaped $(14 \mathrm{G})$, large kill zones are not possible with a single probe. Therefore, large masses may require three or four probes. Each additional probe increases procedure time and the risk of organ injury and bleeding [89].

Interest in and application of cryoablation for HCC treatment have increased. Although some early review articles reported insufficient data to support or refute cryotherapy for HCC [90], many recent studies have shown that image-guided percutaneous cryoablation is safe and effective for treating HCC [82-84, 91, 92]. A single meta-analysis performed by Huang et 
al. [93] investigated the role of cryoablation in comparison to RFA in treating unresectable HCC and showed an advantage for RFA over cryotherapy in terms of complication rates (OR 2.80; 95\% CI, 1.54-5.09) and local tumor recurrence (OR 1.96; 95\% CI, 1.12-3.42). However, multiple confounders exist in clinical trials, especially the bias in patient selection. A recent study [94], comparing cryoablation with RFA-MWA for treating HCCs sized $<5 \mathrm{~cm}$, showed that cryoablation can provide significantly improved local control for HCCs sized $>2 \mathrm{~cm}$ compared with RFA-MWA. Another multicenter RCT [95] comparing the outcomes of percutaneous cryoablation with RFA for treating HCCs has been published very recently. The authors concluded that in HCC patients with Child-Pugh class A-B cirrhosis, HCC lesions $\leq 4$ $\mathrm{cm}$, and no more than two lesions in total, percutaneous cryoablation and RFA are equally safe and effective ablation treatments. For HCCs sized 3.1-4.0 cm, percutaneous cryoablation is associated with a lower rate of local tumor progression compared with RFA and should be considered one of the standard local ablation modalities.

\section{Other Local Ablative Techniques}

\section{Percutaneous Ethanol Injection}

$\mathrm{PEI}$ is the most common method of chemical ablation. It relies on the dispersion of ethanol within the lesion, which results in coagulation necrosis. PEI is a well-established technique for treating HCC tumors $<3 \mathrm{~cm}$ in size [96]. Although it is not affected by heat sink, its success is largely limited by the difficulty of obtaining a uniform distillation of ethanol over a large tumor volume. Multiple studies have demonstrated the superiority of RFA to PEI for treating early-stage HCC [11-15]. Hence, PEI has largely been replaced by these modalities in treating HCC. However, owing to its ease of use and cost-effectiveness, PEI remains a viable option in many parts of the world.

\section{Irreversible Electroporation}

Irreversible electroporation (IRE) is the newest commercially available percutaneous ablation technique, which uses pulses of a high electrical current to induce irreversible disruption of cell membrane integrity, resulting in cell death via both apoptosis and coagulation necrosis $[97,98]$. Two main potential advantages of IRE are that it creates tissue ablation in a manner independent of heat generation and does not affect the extracellular matrix, thus allowing for both a reduction in the heat sink effect and maintenance of structural integrity of the adjacent blood vessels and bile ducts $[99,100]$. Several small series have evaluated the safety and efficacy of IRE for hepatic tumors. However, further prospective clinical trials are strongly needed to determine the optimal effectiveness of IRE for treating HCC.

\section{Percutaneous Laser Ablation}

Percutaneous laser ablation (PLA), which involves the direct deposition of laser light via fiber-optic applicators to induce tissue hyperthermia in tumors, is a recent technique that has also been proposed as an active treatment for patients with HCC [101-104]. Pacella et al. [105] retrospectively analyzed the use of PLA for treating nonsurgical early HCC and showed an initial complete response in 338 patients (78\%) with a median OS of 47 months. A recent prospective randomized study has compared PLA $(n=15)$ and RFA $(n=15)$ for treating HCC $\leq 4 \mathrm{~cm}$ in patients with liver cirrhosis. A complete response was obtained in $87 \%$ of the lesions treated with PLA and in $93 \%$ of the lesions treated with RFA. The overall local recurrence-free survival rates at 3,6, and 12 months were comparable with a higher rate of recurrence in the PLA group for lesions $\geq 21 \mathrm{~mm}$. However, currently sufficient prospective data comparing the treatment efficacy in terms of long survival between PLA and other local ablative therapies are lacking. 


\section{Transarterial Therapy}

\section{Transarterial Chemoembolization}

TACE is considered first-line therapy for patients with intermediate-stage HCC (multinodular, relatively preserved liver function, absence of cancer-related symptoms, and no evidence of vascular invasion or extrahepatic spread) $[8,106]$. The recommendation for TACE as the standard treatment for intermediate-stage HCC is based on the results of two positive RCTs and a meta-analysis, which demonstrated improved survival in patients with HCC treated with TACE compared with best supportive care $[7,107,108]$. TACE also can be used as a bridge therapy before transplantation, by keeping tumors within the size and number required for transplantation [109]. The basis for TACE is the image-guided delivery of chemotherapeutic agents frequently embedded in Lipiodol into the tumor-feeding vessel, followed by embolization of the blood vessel with embolic agents [110-112]. Embolization is feasible and effective in treating HCC primarily based on the dominant arterial vascular supply of HCC compared with the normal liver parenchyma, which is largely supplied by the portal vein [113]. Occlusion of the terminal vasculature feeding the tumor results in ischemia and subsequent coagulation necrosis but typically spares adjacent liver cells as the portal vein remains patent. In addition, the targeted delivery of chemotherapeutic agents would result in high local concentrations, thereby leading to significant antitumor efficacy.

TACE is a highly complex and operator-dependent procedure. Heterogeneity exists in techniques, tumor burden, liver function (Child-Pugh class A or B), and agents used, which might explain the variations in outcomes in patients with HCC treated with TACE [114]. Achieving the best outcomes with TACE relies on appropriate patient selection and an accurate technique. From a technical point of view, more standardization of TACE protocols is still needed. The ideal TACE schedule should achieve a maximal and sustained concentration of the chemotherapeutic drug in the tumor, with minimal systemic exposure combined with the calibrated obstruction of tumor vessels [106].

Drug-eluting bead (DEB)-TACE has shown improved treatment tolerability and efficacy for HCC, as well as facilitated standardization of the procedure due to a high degree of treatment reproducibility. DEBs have the ability to actively sequester a drug from a solution and release it in a controlled and sustained fashion into the tumor vasculature, owing to ion exchange with the surrounding environment $[115,116]$. Unlike the rapid release of the drug from Lipiodol in conventional TACE (c-TACE), DEB-TACE can significantly increase the local concentration of the drug and the antitumoral efficacy, with minimal systemic effects [117]. In addition, DEB-TACE has the important advantage of being a more reproducible technique. The results of the randomized phase II PRECISION V trial [118], which aimed to compare the outcomes of DEB-TACE with c-TACE for treating HCC, demonstrated that DEB-TACE with doxorubicin as the chemotherapeutic agent was better tolerated than c-TACE with doxorubicin, owing to a significant reduction in doxorubicin-related adverse events. Moreover, the use of DEBs also significantly improved the objective response rate in patients with ChildPugh class B bilobar disease and recurrent disease [118]. More recent results of two RCTs have been published, with one trial showing equivalent survival rates [119] and the other demonstrating a better treatment response and delayed tumor progression for DEB-TACE in comparison with c-TACE [120].

Despite the recent advances and technical refinements, the efficacy of TACE is still limited by the dual blood supply of liver tumors, which makes it impossible to achieve sufficient tumor ischemia without irreversible damage to the surrounding normal liver parenchyma. Modified TACE procedures, such as superselective TACE, selective balloon-occluded TACE, and TACE under balloon occlusion of the hepatic vein or the corresponding portal vein branch, 
have been developed to obtain a complete necrosis of the tumor [121]. Alternative strategies, including the combination of systemic therapy with TACE, have also been investigated to improve TACE-based regimens. Given that TACE induces a posttreatment surge of VEGF (vascular endothelial growth factor) due to local hypoxia [122,123], the combination of TACE with anti-VEGF therapy may be an effective strategy to improve outcomes for these patients. A prospective single-center phase II study comparing the advent of sorafenib treatment with placebo 1 week after TACE demonstrated a disease control rate of 95\% with manageable toxicity [124]. In contrast, a randomized phase III study with sorafenib beginning 1-3 months after TACE failed to show a survival benefit [125]. The optimal scheduling of antiangiogenic agents with TACE is essential to improve patients' prognosis.

\section{Transarterial Radioembolization}

Radioembolization, which refers to the intra-arterial administration of ${ }^{90}$ Y-loaded beads that lodge in the arteriolar circulation supplying tumors and deliver tumoricidal radiation, has emerged as a potential option in patients with limited hepatic reserve. It evolved out of the inability of external beam radiation to deliver high doses without causing radiation hepatitis [126]. In contrast to external beam radiation, which can only deliver 30-35 Gy of radiation before causing clinically significant hepatotoxicity, intra-arterial ${ }^{90} \mathrm{Y}$ can deliver up to 150 Gy $[127,128]$. Moreover, ${ }^{90} \mathrm{Y}$ beads lodge preferentially in the tumor vasculature and have a limited treatment zone, thus maximizing radiation to the tumor and minimizing it to the hepatic parenchyma. The safety and efficacy of ${ }^{90} \mathrm{Y}$ radioembolization have been demonstrated in a number of studies [129-132]. In 2011, Salem et al. [133] performed a retrospective study comparing the outcomes of radioembolization and TACE. Although no significant difference in survival time was observed, radioembolization resulted in a longer time to progression and produced less toxicity than TACE. Moreover, compared with TACE, radioembolization is safe for use in patients with portal vein thrombosis, due to its minimal embolic effect [134]. Despite the antitumor activity and promising survival results of radioembolization, further prospective studies, especially RCTs, are needed to provide the highest level of evidence.

\section{Image-Guided ${ }^{125}$ I Seed Implant Brachytherapy}

Iodine-125 $\left({ }^{125} \mathrm{I}\right)$ is a nuclide that emits gamma rays with a very low average energy, a long half-life of 60 days, and a radiation diameter of $2 \mathrm{~cm}$ for tissue and $0.025 \mathrm{~mm}$ for lead [135]. Image-guided ${ }^{125}$ I seed implant brachytherapy can achieve a necrotizing dose irradiation within the target volumes with a very sharp falloff outside the implanted area, thus sparing the normal tissues around the lesion. It has been widely used for a variety of tumors, including prostatic cancer [136], pancreatic cancer [137], pulmonary cancer [138], and head and neck cancers [139]. More importantly, based on its favorable therapeutic efficacy [140],

${ }^{125}$ I seed implant brachytherapy is now recognized as a standard treatment for patients with localized low-risk prostate cancer. In terms of HCC, a recent study has evaluated the feasibility and therapeutic efficacy of 1.5-tesla conventional magnetic resonance-guided percutaneous interstitial ${ }^{125}$ I seed implant brachytherapy [141]. However, strong evidence which would justify the use of ${ }^{125}$ I seed implant brachytherapy alone for HCC is still insufficient. ${ }^{125}$ I seed implant brachytherapy might be indicated in highly selected patients with high-risk, localized HCCs, such as those adjacent to large vessels being susceptible to a heat sink effect. Moreover, ${ }^{125}$ I seed implant brachytherapy in combination with other locoregional therapy may lead to better control of HCC. 


\section{Conclusion and Future Directions}

Image-guided locoregional therapies for HCC with both local ablative and transarterial therapeutic techniques have become common since the advent of modern imaging. Impressive progress in locoregional therapies has been made with a parallel continuous advance in technical developments. For example, energy-based techniques such as RFA and MWA, which were historically limited to lesions $<3 \mathrm{~cm}$, have benefited from recent advances in technology that have expanded their capability to up to $5 \mathrm{~cm}$. Likewise, transarterial therapy, which was historically limited to intermediate-stage HCC, has expanded its role in treating HCC with portal vein thrombosis after introduction of transarterial radioembolization. Moreover, combination treatment modalities (thermal-based ablation and TACE) have shown promising results compared with single-therapy treatment for large tumors $(<7 \mathrm{~cm})$, which have consequently broadened their clinical indications.

Despite significant improvement, long-term survival outcomes in patients treated with these techniques are still not fully satisfactory, due to the high rates of tumor recurrence. The use of localized radiation in combination with thermal ablation is of particular interest for future investigation, as both improved local and intrahepatic tumor control and long-term survival have been demonstrated in a recent RCT. Tumor-specific immune responses have been reported to be activated after thermal ablative therapies, and, therefore, they represent potential interesting combination partners for thermal-based ablative approaches in HCC. Finally, tumor-targeting gene therapy may offer an intriguing area of future research. Intraarterial delivery of both viral and nonviral vectors (nanocomposites or iodized oil) may improve, respectively, the safety profile of and concentrations usable in these two approaches.

\section{Disclosure Statement}

No potential conflicts of interest are disclosed.

\section{References}

$>1$ European Association for the Study of the Liver; European Organisation for Research and Treatment of Cancer: EASL-EORTC clinical practice guidelines: management of hepatocellular carcinoma. J Hepatol 2012; 56:908-943.

2 Villanueva A, Hernandez-Gea V, Llovet JM: Medical therapies for hepatocellular carcinoma: a critical view of the evidence. Nat Rev Gastroenterol Hepatol 2013;10:34-42.

-3 Forner A, Reig ME, de Lope CR, Bruix J: Current strategy for staging and treatment: the BCLC update and future prospects. Semin Liver Dis 2010;30:61-74.

4 Pawlik TM, Delman KA, Vauthey JN, et al: Tumor size predicts vascular invasion and histologic grade: implications for selection of surgical treatment for hepatocellular carcinoma. Liver Transpl 2005;11:1086-1092.

5 Poon RT, Fan ST, Lo CM, Liu CL, Wong J: Long-term survival and pattern of recurrence after resection of small hepatocellular carcinoma in patients with preserved liver function: implications for a strategy of salvage transplantation. Ann Surg 2002;235:373-382.

6 Clavien PA, Lesurtel M, Bossuyt PM, Gores GJ, Langer B, Perrier A; OLT for HCC Consensus Group: Recommendations for liver transplantation for hepatocellular carcinoma: an international consensus conference report. Lancet Oncol 2012;13:e11-e22.

7 Llovet JM, Bruix J: Systematic review of randomized trials for unresectable hepatocellular carcinoma: chemoembolization improves survival. Hepatology 2003;37:429-442.

-8 Bruix J, Sherman M; Practice Guidelines Committee, American Association for the Study of Liver Diseases: Management of hepatocellular carcinoma. Hepatology 2005;42:1208-1236.

-9 Huang J, Yan L, Cheng Z, et al: A randomized trial comparing radiofrequency ablation and surgical resection for HCC conforming to the Milan criteria. Ann Surg 2010;252:903-912.

$\checkmark 10$ McGahan JP, Brock JM, Tesluk H, Gu WZ, Schneider P, Browning PD: Hepatic ablation with use of radiofrequency electrocautery in the animal model. J Vasc Interv Radiol 1992;3:291-297. 
11 Lencioni RA, Allgaier HP, Cioni D, et al: Small hepatocellular carcinoma in cirrhosis: randomized comparison of radio-frequency thermal ablation versus percutaneous ethanol injection. Radiology 2003;228:235-240.

12 Lin SM, Lin CJ, Lin CC, Hsu CW, Chen YC: Radiofrequency ablation improves prognosis compared with ethanol injection for hepatocellular carcinoma $<$ or $=4 \mathrm{~cm}$. Gastroenterology 2004;127:1714-1723.

-13 Shiina S, Teratani T, Obi S, et al: A randomized controlled trial of radiofrequency ablation with ethanol injection for small hepatocellular carcinoma. Gastroenterology 2005;129:122-130.

14 Lin SM, Lin CJ, Lin CC, Hsu CW, Chen YC: Randomised controlled trial comparing percutaneous radiofrequency thermal ablation, percutaneous ethanol injection, and percutaneous acetic acid injection to treat hepatocellular carcinoma of $3 \mathrm{~cm}$ or less. Gut 2005;54:1151-1156.

15 Brunello F, Veltri A, Carucci P, et al: Radiofrequency ablation versus ethanol injection for early hepatocellular carcinoma: a randomized controlled trial. Scand J Gastroenterol 2008;43:727-735.

16 Orlando A, Leandro G, Olivo M, Andriulli A, Cottone M: Radiofrequency thermal ablation vs percutaneous ethanol injection for small hepatocellular carcinoma in cirrhosis: meta-analysis of randomized controlled trials. Am J Gastroenterol 2009;104:514-524.

17 Cho YK, Kim JK, Kim MY, Rhim H, Han JK: Systematic review of randomized trials for hepatocellular carcinoma treated with percutaneous ablation therapies. Hepatology 2009;49:453-459.

18 Germani G, Pleguezuelo M, Gurusamy K, Meyer T, Isgrò G, Burroughs AK: Clinical outcomes of radiofrequency ablation, percutaneous alcohol and acetic acid injection for hepatocelullar [hepatocellular] carcinoma: a metaanalysis. J Hepatol 2010;52:380-388.

19 Shen A, Zhang H, Tang C, Chen Y, Wang Y, Zhang C, Wu Z: Systematic review of radiofrequency ablation versus percutaneous ethanol injection for small hepatocellular carcinoma up to $3 \mathrm{~cm}$. J Gastroenterol Hepatol 2013; 28:793-800.

20 Feng K, Yan J, Li X, et al: A randomized controlled trial of radiofrequency ablation and surgical resection in the treatment of small hepatocellular carcinoma. J Hepatol 2012;57:794-802.

21 Liu Z, Zhou Y, Zhang P, Qin H: Meta-analysis of the therapeutic effect of hepatectomy versus radiofrequency ablation for the treatment of hepatocellular carcinoma. Surg Laparosc Endosc Percutan Tech 2010;20:130140.

22 Zhou Y, Zhao Y, Li B, Xu D, Yin Z, Xie F, Yang J: Meta-analysis of radiofrequency ablation versus hepatic resection for small hepatocellular carcinoma. BMC Gastroenterol 2010;10:78.

23 Livraghi T, Goldberg SN, Lazzaroni S, Meloni F, Ierace T, Solbiati L, Gazelle GS: Hepatocellular carcinoma: radio-frequency ablation of medium and large lesions. Radiology 2000;214:761-768.

24 Lu DS, Raman SS, Vodopich DJ, Wang M, Sayre J, Lassman C: Effect of vessel size on creation of hepatic radiofrequency lesions in pigs: assessment of the 'heat sink' effect. AJR Am J Roentgenol 2002;178:47-51.

-25 Lu DS, Yu NC, Raman SS, et al: Radiofrequency ablation of hepatocellular carcinoma: treatment success as defined by histologic examination of the explanted liver. Radiology 2005;234:954-960.

-26 Goldberg SN, Hahn PF, Halpern EF, Fogle RM, Gazelle GS: Radio-frequency tissue ablation: effect of pharmacologic modulation of blood flow on coagulation diameter. Radiology 1998;209:761-767.

27 Horkan C, Ahmed M, Liu Z, Gazelle GS, Solazzo SA, Kruskal JB, Goldberg SN: Radiofrequency ablation: effect of pharmacologic modulation of hepatic and renal blood flow on coagulation diameter in a VX2 tumor model. J Vasc Interv Radiol 2004;15:269-274.

28 Hines-Peralta A, Sukhatme V, Regan M, Signoretti S, Liu ZJ, Goldberg SN: Improved tumor destruction with arsenic trioxide and radiofrequency ablation in three animal models. Radiology 2006;240:82-89.

29 Feng X, Xu R, Du X, et al: Combination therapy with sorafenib and radiofrequency ablation for BCLC Stage 0-B1 hepatocellular carcinoma: a multicenter retrospective cohort study. Am J Gastroenterol 2014;109:18911899.

-30 de Baere T, Bessoud B, Dromain C, et al: Percutaneous radiofrequency ablation of hepatic tumors during temporary venous occlusion. AJR Am J Roentgenol 2002;178:53-59.

-31 Yamasaki T, Kurokawa F, Shirahashi H, Kusano N, Hironaka K, Okita K: Percutaneous radiofrequency ablation therapy for patients with hepatocellular carcinoma during occlusion of hepatic blood flow. Comparison with standard percutaneous radiofrequency ablation therapy. Cancer 2002;95:2353-2360.

32 Xu C, Lv PH, Huang XE, Wang SX, Sun L, Wang FA: Efficacy of transarterial chemoembolization combined with radiofrequency ablation in treatment of hepatocellular carcinoma. Asian Pac J Cancer Prev 2015;16:61596162.

-33 Liang HY, Guo QY, Sun W, et al: Sequential use of transhepatic arterial chemoembolization and bipolar radiofrequency ablation in the clinical therapy of hepatocellular carcinoma. Cancer Biother Radiopharm 2015;30: 427-432.

-34 Veltri A, Moretto P, Doriguzzi A, Pagano E, Carrara G, Gandini G: Radiofrequency thermal ablation (RFA) after transarterial chemoembolization (TACE) as a combined therapy for unresectable non-early hepatocellular carcinoma (HCC). Eur Radiol 2006;16:661-669.

-35 Helmberger T, Dogan S, Straub G, et al: Liver resection or combined chemoembolization and radiofrequency ablation improve survival in patients with hepatocellular carcinoma. Digestion 2007;75:104-112.

36 Shibata T, Isoda H, Hirokawa Y, Arizono S, Shimada K, Togashi K: Small hepatocellular carcinoma: is radiofrequency ablation combined with transcatheter arterial chemoembolization more effective than radiofrequency ablation alone for treatment? Radiology 2009;252:905-913. 
-37 Kim JH, Won HJ, Shin YM, Kim SH, Yoon HK, Sung KB, Kim PN: Medium-sized (3.1-5.0 cm) hepatocellular carcinoma: transarterial chemoembolization plus radiofrequency ablation versus radiofrequency ablation alone. Ann Surg Oncol 2011;18:1624-1629.

-38 Peng ZW, Zhang YJ, Liang HH, Lin XJ, Guo RP, Chen MS: Recurrent hepatocellular carcinoma treated with sequential transcatheter arterial chemoembolization and RF ablation versus RF ablation alone: a prospective randomized trial. Radiology 2012;262:689-700.

39 Kim JW, Kim JH, Won HJ, Shin YM, Yoon HK, Sung KB, Kim PN: Hepatocellular carcinomas 2-3 cm in diameter: transarterial chemoembolization plus radiofrequency ablation versus radiofrequency ablation alone. Eur J Radiol 2012;81:e189-e193.

40 Takaki H, Yamakado K, Nakatsuka A, Fuke H, Murata K, Shiraki K, Takeda K: Radiofrequency ablation combined with chemoembolization for the treatment of hepatocellular carcinomas $5 \mathrm{~cm}$ or smaller: risk factors for local tumor progression. J Vasc Interv Radiol 2007;18:856-861.

41 Morimoto M, Numata K, Kondou M, Nozaki A, Morita S, Tanaka K: Midterm outcomes in patients with intermediate-sized hepatocellular carcinoma: a randomized controlled trial for determining the efficacy of radiofrequency ablation combined with transcatheter arterial chemoembolization. Cancer 2010;116:5452-5460.

42 Peng ZW, Zhang YJ, Chen MS, et al: Radiofrequency ablation with or without transcatheter arterial chemoembolization in the treatment of hepatocellular carcinoma: a prospective randomized trial. J Clin Oncol 2013;31: 426-432.

43 Lu Z, Wen F, Guo Q, Liang H, Mao X, Sun H: Radiofrequency ablation plus chemoembolization versus radiofrequency ablation alone for hepatocellular carcinoma: a meta-analysis of randomized-controlled trials. Eur J Gastroenterol Hepatol 2013;25:187-194.

-44 Ni JY, Liu SS, Xu LF, Sun HL, Chen YT: Meta-analysis of radiofrequency ablation in combination with transarterial chemoembolization for hepatocellular carcinoma. World J Gastroenterol 2013;19:3872-3882.

45 Jiang G, Xu X, Ren S, Wang L: Combining transarterial chemoembolization with radiofrequency ablation for hepatocellular carcinoma. Tumour Biol 2014;35:3405-3408.

-46 Chen QW, Ying HF, Gao S, et al: Radiofrequency ablation plus chemoembolization versus radiofrequency ablation alone for hepatocellular carcinoma: a systematic review and meta-analysis. Clin Res Hepatol Gastroenterol 2015, Epub ahead of print.

47 Lin ZY, Chen J, Deng XF: Treatment of hepatocellular carcinoma adjacent to large blood vessels using 1.5T MRIguided percutaneous radiofrequency ablation combined with iodine- 125 radioactive seed implantation. Eur J Radiol 2012;81:3079-3083.

48 Chen K, Chen G, Wang H, et al: Increased survival in hepatocellular carcinoma with iodine-125 implantation plus radiofrequency ablation: a prospective randomized controlled trial. J Hepatol 2014;61:1304-1311.

49 Livraghi T, Solbiati L, Meloni MF, Gazelle GS, Halpern EF, Goldberg SN: Treatment of focal liver tumors with percutaneous radio-frequency ablation: complications encountered in a multicenter study. Radiology 2003; 226:441-451.

50 Llovet JM, Vilana R, Bru C, et al: Increased risk of tumor seeding after percutaneous radiofrequency ablation for single hepatocellular carcinoma. Hepatology 2001;33:1124-1129.

51 Teratani T, Yoshida H, Shiina S, et al: Radiofrequency ablation for hepatocellular carcinoma in so-called highrisk locations. Hepatology 2006;43:1101-1108.

52 Santambrogio R, Barabino M, Bruno S, et al: Long-term outcome of laparoscopic ablation therapies for unresectable hepatocellular carcinoma: a single European center experience of 426 patients. Surg Endosc 2015, Epub ahead of print.

53 de la Serna S, Vilana R, Sánchez-Cabús S, et al: Results of laparoscopic radiofrequency ablation for HCC. Could the location of the tumour influence a complete response to treatment? A single European centre experience. HPB (Oxford) 2015;17:387-393.

54 Simon CJ, Dupuy DE, Mayo-Smith WW: Microwave ablation: principles and applications. Radiographics 2005; 25(suppl 1):S69-S83.

55 Ahmed M, Brace CL, Lee FT Jr, Goldberg SN: Principles of and advances in percutaneous ablation. Radiology 2011;258:351-369.

56 Yu NC, Raman SS, Kim YJ, Lassman C, Chang X, Lu DS: Microwave liver ablation: influence of hepatic vein size on heat-sink effect in a porcine model. J Vasc Interv Radiol 2008;19:1087-1092.

57 Schramm W, Yang D, Wood BJ, Rattay F, Haemmerich D: Contribution of direct heating, thermal conduction and perfusion during radiofrequency and microwave ablation. Open Biomed Eng J 2007;1:47-52.

58 Andreano A, Huang Y, Meloni MF, Lee FT Jr, Brace C: Microwaves create larger ablations than radiofrequency when controlled for power in ex vivo tissue. Med Phys 2010;37:2967-2973.

59 Andreano A, Brace CL: A comparison of direct heating during radiofrequency and microwave ablation in ex vivo liver. Cardiovasc Intervent Radiol 2013;36:505-511.

60 Fan W, Li X, Zhang L, Jiang H, Zhang J: Comparison of microwave ablation and multipolar radiofrequency ablation in vivo using two internally cooled probes. AJR Am J Roentgenol 2012;198:W46-W50.

61 Dong B, Liang P, Yu X, Su L, Yu D, Cheng Z, Zhang J: Percutaneous sonographically guided microwave coagulation therapy for hepatocellular carcinoma: results in 234 patients. AJR Am J Roentgenol 2003;180:15471555.

62 Liang P, Dong B, Yu X, Yu D, Wang Y, Feng L, Xiao Q: Prognostic factors for survival in patients with hepatocellular carcinoma after percutaneous microwave ablation. Radiology 2005;235:299-307. 
63 Groeschl RT, Pilgrim CH, Hanna EM, et al: Microwave ablation for hepatic malignancies: a multiinstitutional analysis. Ann Surg 2014;259:1195-1200.

64 Huang S, Yu J, Liang P, Yu X, Cheng Z, Han Z, Li Q: Percutaneous microwave ablation for hepatocellular carcinoma adjacent to large vessels: a long-term follow-up. Eur J Radiol 2014;83:552-558.

65 Sun AX, Cheng ZL, Wu PP, et al: Clinical outcome of medium-sized hepatocellular carcinoma treated with microwave ablation. World J Gastroenterol 2015;21:2997-3004.

66 Leung U, Kuk D, D’Angelica MI, et al: Long-term outcomes following microwave ablation for liver malignancies. Br J Surg 2015;102:85-91.

67 Ziemlewicz TJ, Hinshaw JL, Lubner MG, Brace CL, Alexander ML, Agarwal P, Lee FT Jr: Percutaneous microwave ablation of hepatocellular carcinoma with a gas-cooled system: initial clinical results with 107 tumors. J Vasc Interv Radiol 2015;26:62-68.

68 Shibata T, Iimuro Y, Yamamoto Y, Maetani Y, Ametani F, Itoh K, Konishi J: Small hepatocellular carcinoma: comparison of radio-frequency ablation and percutaneous microwave coagulation therapy. Radiology 2002; 223:331-337.

69 Lu MD, Xu HX,Xie XY, et al: Percutaneous microwave and radiofrequency ablation for hepatocellular carcinoma: a retrospective comparative study. J Gastroenterol 2005;40:1054-1060.

70 Simo KA, Sereika SE, Newton KN, Gerber DA: Laparoscopic-assisted microwave ablation for hepatocellular carcinoma: safety and efficacy in comparison with radiofrequency ablation. J Surg Oncol 2011;104:822-829.

-71 Qian GJ, Wang N, Shen Q, et al: Efficacy of microwave versus radiofrequency ablation for treatment of small hepatocellular carcinoma: experimental and clinical studies. Eur Radiol 2012;22:1983-1990.

72 Ding J, Jing X, Liu J, Wang Y, Wang F, Wang Y, Du Z: Comparison of two different thermal techniques for the treatment of hepatocellular carcinoma. Eur J Radiol 2013;82:1379-1384.

-73 Abdelaziz A, Elbaz T, Shousha HI, Mahmoud S, Ibrahim M, Abdelmaksoud A, Nabeel M: Efficacy and survival analysis of percutaneous radiofrequency versus microwave ablation for hepatocellular carcinoma: an Egyptian multidisciplinary clinic experience. Surg Endosc 2014;28:3429-3434.

74 Zhang XG, Zhang ZL, Hu SY, Wang YL: Ultrasound-guided ablative therapy for hepatic malignancies: a comparison of the therapeutic effects of microwave and radiofrequency ablation. Acta Chir Belg 2014;114: $40-45$.

75 Yu NC, Lu DS, Raman SS, et al: Hepatocellular carcinoma: microwave ablation with multiple straight and loop antenna clusters - pilot comparison with pathologic findings. Radiology 2006;239:269-275.

76 Liu Y, Zheng Y, Li S, Li B, Zhang Y, Yuan Y: Percutaneous microwave ablation of larger hepatocellular carcinoma. Clin Radiol 2013;68:21-26.

-77 Xu LF, Sun HL, Chen YT, et al: Large primary hepatocellular carcinoma: transarterial chemoembolization monotherapy versus combined transarterial chemoembolization-percutaneous microwave coagulation therapy. J Gastroenterol Hepatol 2013;28:456-463.

-78 Abdelaziz A0, Nabeel MM, Elbaz TM, et al: Microwave ablation versus transarterial chemoembolization in large hepatocellular carcinoma: prospective analysis. Scand J Gastroenterol 2015;50:479-484.

79 Copper IS: Cryogenic surgery: a new method of destruction or extirpation of benign or malignant tissues. N Engl J Med 1963;268:743-749.

80 Hoffmann NE, Bischof JC: The cryobiology of cryosurgical injury. Urology 2002;60:40-49.

81 Maccini M, Sehrt D, Pompeo A, Chicoli FA, Molina WR, Kim FJ: Biophysiologic considerations in cryoablation: a practical mechanistic molecular review. Int Braz J Urol 2011;37:693-696.

82 Orlacchio A, Bazzocchi G, Pastorelli D, et al: Percutaneous cryoablation of small hepatocellular carcinoma with US guidance and CT monitoring: initial experience. Cardiovasc Intervent Radiol 2008;31:587-594.

83 Chen HW, Lai EC, Zhen ZJ, Cui WZ, Liao S, Lau WY: Ultrasound-guided percutaneous cryotherapy of hepatocellular carcinoma. Int J Surg 2011;9:188-191.

84 Shimizu T, Sakuhara Y, Abo D, et al: Outcome of MR-guided percutaneous cryoablation for hepatocellular carcinoma. J Hepatobiliary Pancreat Surg 2009;16:816-823.

-85 Allaf ME, Varkarakis IM, Bhayani SB, Inagaki T, Kavoussi LR, Solomon SB: Pain control requirements for percutaneous ablation of renal tumors: cryoablation versus radiofrequency ablation - initial observations. Radiology 2005;237:366-370.

86 Sung GT, Gill IS, Hsu TH, Meraney AM, Skacel M, Brainard JA, Remer EM: Effect of intentional cryo-injury to the renal collecting system. J Urol 2003;170(pt 1):619-622.

87 Seifert JK, Morris DL: World survey on the complications of hepatic and prostate cryotherapy. World J Surg 1999;23:109-113; discussion 113-114.

88 Smith MT, Ray CE: The treatment of primary and metastatic hepatic neoplasms using percutaneous cryotherapy. Semin Intervent Radiol 2006;23:39-46.

89 Bilchik AJ, Wood TF, Allegra D, et al: Cryosurgical ablation and radiofrequency ablation for unresectable hepatic malignant neoplasms: a proposed algorithm. Arch Surg 2000;135:657-662; discussion 662-664.

$\$ 90$ Awad T, Thorlund K, Gluud C: Cryotherapy for hepatocellular carcinoma. Cochrane Database Syst Rev 2009; 4:CD007611.

91 Wang C, Lu Y, Chen Y, et al: Prognostic factors and recurrence of hepatitis B-related hepatocellular carcinoma after argon-helium cryoablation: a prospective study. Clin Exp Metastasis 2009;26:839-848.

$\$ 92$ Yang Y, Wang C, Lu Y, et al: Outcomes of ultrasound-guided percutaneous argon-helium cryoablation of hepatocellular carcinoma. J Hepatobiliary Pancreat Sci 2012;19:674-684. 
Shi and Zhai: A Recent Advance in Image-Guided Locoregional Therapy for Hepatocellular Carcinoma

93 Huang YZ, Zhou SC, Zhou H, Tong M: Radiofrequency ablation versus cryosurgery ablation for hepatocellular carcinoma: a meta-analysis. Hepatogastroenterology 2013;60:1131-1135.

94 Ei S, Hibi T, Tanabe M, et al: Cryoablation provides superior local control of primary hepatocellular carcinomas of $>2 \mathrm{~cm}$ compared with radiofrequency ablation and microwave coagulation therapy: an underestimated tool in the toolbox. Ann Surg Oncol 2015;22:1294-1300.

95 Wang C, Wang H, Yang W, et al: Multicenter randomized controlled trial of percutaneous cryoablation versus radiofrequency ablation in hepatocellular carcinoma. Hepatology 2015;61:1579-1590.

-96 Vilana R, Bruix J, Bru C, Ayuso C, Solé M, Rodés J: Tumor size determines the efficacy of percutaneous ethanol injection for the treatment of small hepatocellular carcinoma. Hepatology 1992;16:353-357.

97 Lencioni R, Cioni D, Della Pina C, Crocetti L: Hepatocellular carcinoma: new options for image-guided ablation. J Hepatobiliary Pancreat Sci 2010;17:399-403.

98 Narayanan G: Irreversible electroporation for treatment of liver cancer. Gastroenterol Hepatol (NY) 2011;7: 313-316.

99 Maor E, Ivorra A, Leor J, Rubinsky B: The effect of irreversible electroporation on blood vessels. Technol Cancer Res Treat 2007;6:307-312.

100 Charpentier KP, Wolf F, Noble L, Winn B, Resnick M, Dupuy DE: Irreversible electroporation of the liver and liver hilum in swine. HPB (Oxford) 2011;13:168-173.

101 Pacella CM, Bizzarri G, Francica G, et al: Analysis of factors predicting survival in patients with hepatocellular carcinoma treated with percutaneous laser ablation. J Hepatol 2006;44:902-909.

102 Francica G, Petrolati A, Di Stasio E, Pacella S, Stasi R, Pacella CM: Effectiveness, safety, and local progression after percutaneous laser ablation for hepatocellular carcinoma nodules up to $4 \mathrm{~cm}$ are not affected by tumor location. AJR Am J Roentgenol 2012;199:1393-1401.

103 Pacella CM, Bizzarri G, Francica G, et al: Percutaneous laser ablation in the treatment of hepatocellular carcinoma with small tumors: analysis of factors affecting the achievement of tumor necrosis. J Vasc Interv Radiol 2005;16:1447-1457.

104 Pompili M, Pacella CM, Francica G, et al: Percutaneous laser ablation of hepatocellular carcinoma in patients with liver cirrhosis awaiting liver transplantation. Eur J Radiol 2010;74:e6-e11.

105 Pacella CM, Francica G, Di Lascio FM, et al: Long-term outcome of cirrhotic patients with early hepatocellular carcinoma treated with ultrasound-guided percutaneous laser ablation: a retrospective analysis. J Clin Oncol 2009;27:2615-2621.

106 Forner A, Gilabert M, Bruix J, Raoul JL: Treatment of intermediate-stage hepatocellular carcinoma. Nat Rev Clin Oncol 2014;11:525-535.

107 Lo CM, Ngan H, Tso WK, et al: Randomized controlled trial of transarterial Lipiodol chemoembolization for unresectable hepatocellular carcinoma. Hepatology 2002;35:1164-1171.

108 Llovet JM, Real MI, Montana X, et al: Arterial embolisation or chemoembolisation versus symptomatic treatment in patients with unresectable hepatocellular carcinoma: a randomised controlled trial. Lancet 2002;359:1734-1739.

109 Frenette CT, Osorio RC, Stark J, et al: Conventional TACE and drug-eluting bead TACE as locoregional therapy before orthotopic liver transplantation: comparison of explant pathologic response. Transplantation 2014;98: 781-787.

110 Raoul JL, Heresbach D, Bretagne JF, et al: Chemoembolization of hepatocellular carcinomas. A study of the biodistribution and pharmacokinetics of doxorubicin. Cancer 1992;70:585-590.

111 Bruix J, Llovet JM, Castells A, et al: Transarterial embolization versus symptomatic treatment in patients with advanced hepatocellular carcinoma: results of a randomized, controlled trial in a single institution. Hepatology 1998;27:1578-1583.

112 Kwok PC, Lam TW, Chan SC, et al: A randomized clinical trial comparing autologous blood clot and gelfoam in transarterial chemoembolization for inoperable hepatocellular carcinoma. J Hepatol 2000;32:955-964.

113 Bierman HR, Byron RL Jr, Kelley KH, Grady A: Studies on the blood supply of tumors in man. III. Vascular patterns of the liver by hepatic arteriography in vivo. J Natl Cancer Inst 1951;12:107-131.

114 Raoul JL, Sangro B, Forner A, Mazzaferro V, Piscaglia F, Bolondi L, Lencioni R: Evolving strategies for the management of intermediate-stage hepatocellular carcinoma: available evidence and expert opinion on the use of transarterial chemoembolization. Cancer Treat Rev 2011;37:212-220.

115 Hong K, Khwaja A, Liapi E, Torbenson MS, Georgiades CS, Geschwind JF: New intra-arterial drug delivery system for the treatment of liver cancer: preclinical assessment in a rabbit model of liver cancer. Clin Cancer Res 2006;12:2563-2567.

116 Lewis AL, Gonzalez MV, Lloyd AW, et al: DC bead: in vitro characterization of a drug-delivery device for transarterial chemoembolization. J Vasc Interv Radiol 2006;17:335-342.

117 Varela M, Real MI, Burrel M, et al: Chemoembolization of hepatocellular carcinoma with drug eluting beads: efficacy and doxorubicin pharmacokinetics. J Hepatol 2007;46:474-481.

118 Lammer J, Malagari K, Vogl T, et al: Prospective randomized study of doxorubicin-eluting-bead embolization in the treatment of hepatocellular carcinoma: results of the PRECISION V study. Cardiovasc Intervent Radiol 2010;33:41-52.

119 Golfieri R, Giampalma E, Renzulli M, et al: Randomised controlled trial of doxorubicin-eluting beads vs conventional chemoembolisation for hepatocellular carcinoma. Br J Cancer 2014;111:255-264. 
120 Song MJ, Chun HJ, Song DS, et al: Comparative study between doxorubicin-eluting beads and conventional transarterial chemoembolization for treatment of hepatocellular carcinoma. J Hepatol 2012;57:1244-1250.

121 Murata S, Mine T, Sugihara F, et al: Interventional treatment for unresectable hepatocellular carcinoma. World J Gastroenterol 2014;20:13453-13465.

122 Li X, Feng GS, Zheng CS, Zhuo CK, Liu X: Expression of plasma vascular endothelial growth factor in patients with hepatocellular carcinoma and effect of transcatheter arterial chemoembolization therapy on plasma vascular endothelial growth factor level. World J Gastroenterol 2004;10:2878-2882.

123 Wang B, Xu H, Gao ZQ, Ning HF, Sun YQ, Cao GW: Increased expression of vascular endothelial growth factor in hepatocellular carcinoma after transcatheter arterial chemoembolization. Acta Radiol 2008;49:523-529.

124 Pawlik TM, Reyes DK, Cosgrove D, Kamel IR, Bhagat N, Geschwind JF: Phase II trial of sorafenib combined with concurrent transarterial chemoembolization with drug-eluting beads for hepatocellular carcinoma. J Clin Oncol 2011;29:3960-3967.

125 Kudo M, Imanaka K, Chida N, et al: Phase III study of sorafenib after transarterial chemoembolisation in Japanese and Korean patients with unresectable hepatocellular carcinoma. Eur J Cancer 2011;47:2117-2127.

126 Ingold JA, Reed GB, Kaplan HS, Bagshaw MA: Radiation hepatitis. Am J Roentgenol Radium Ther Nucl Med 1965;93:200-208.

127 Geschwind JF, Salem R, Carr BI, et al: Yttrium-90 microspheres for the treatment of hepatocellular carcinoma. Gastroenterology 2004;127:S194-S205.

128 Sangro B, Iñarrairaegui M, Bilbao JI: Radioembolization for hepatocellular carcinoma. J Hepatol 2012;56:464473.

129 Salem R, Lewandowski RJ, Atassi B, et al: Treatment of unresectable hepatocellular carcinoma with use of ${ }^{90} \mathrm{Y}$ microspheres (TheraSphere): safety, tumor response, and survival. J Vasc Interv Radiol 2005;16:1627-1639.

130 Sangro B, Bilbao JI, Boan J, et al: Radioembolization using ${ }^{90}$ Y-resin microspheres for patients with advanced hepatocellular carcinoma. Int J Radiat Oncol Biol Phys 2006;66:792-800.

131 Kulik LM, Carr BI, Mulcahy MF, et al: Safety and efficacy of ${ }^{90}$ Y radiotherapy for hepatocellular carcinoma with and without portal vein thrombosis. Hepatology 2008;47:71-81.

132 Hilgard P, Hamami M, Fouly AE, et al: Radioembolization with yttrium-90 glass microspheres in hepatocellular carcinoma: European experience on safety and long-term survival. Hepatology 2010;52:1741-1749.

133 Salem R, Lewandowski RJ, Kulik L, et al: Radioembolization results in longer time-to-progression and reduced toxicity compared with chemoembolization in patients with hepatocellular carcinoma. Gastroenterology 2011;140:497-507.e2.

134 Iñarrairaegui M, Thurston KG, Bilbao JI, et al: Radioembolization with use of yttrium-90 resin microspheres in patients with hepatocellular carcinoma and portal vein thrombosis. J Vasc Interv Radiol 2010;21:12051212.

135 Schwarz SB, Thon N, Nikolajek K, Niyazi M, Tonn JC, Belka C, Kreth FW: Iodine-125 brachytherapy for brain tumours - a review. Radiat Oncol 2012;7:30

136 Dickinson PD, Malik J, Mandall P, et al: Five-year outcomes after iodine-125 seed brachytherapy for low-risk prostate cancer at three cancer centres in the UK. BJU Int 2014;113:748-753.

137 Zhongmin W, Yu L, Fenju L, Kemin C, Gang H: Clinical efficacy of CT-guided iodine-125 seed implantation therapy in patients with advanced pancreatic cancer. Eur Radiol 2010;20:1786-1791.

138 Wang ZM, Lu J, Liu T, Chen KM, Huang G, Liu FJ: CT-guided interstitial brachytherapy of inoperable non-small cell lung cancer. Lung Cancer 2011;74:253-257.

139 Jiang YL, Meng N, Wang JJ, Ran WQ, Yuan HS, Qu A, Yang RJ: Percutaneous computed tomography/ultrasonography-guided permanent iodine-125 implantation as salvage therapy for recurrent squamous cell cancers of head and neck. Cancer Biol Ther 2010;9:959-966.

140 Hinnen KA, Schaapveld M, van Vulpen M, et al: Prostate brachytherapy and second primary cancer risk: a competitive risk analysis. J Clin Oncol 2011;29:4510-4515.

141 Lin ZY, Lin J, Lin C, et al: 1.5T conventional MR-guided iodine-125 interstitial implants for hepatocellular carcinoma: feasibility and preliminary clinical experience. Eur J Radiol 2012;81:1420-1425. 